\title{
Simulating markets for ticket sales to major events
}

\author{
$\underline{\text { L.K. Walker }}^{\text {a }}$ \\ ${ }^{a}$ Swinburne University of Technology, Melbourne, Australia \\ Email:lwalker@swin.edu.au
}

\begin{abstract}
One of the advantages of living in a major metropolitan centre is the access to major sporting, musical and cultural events. However, in recent years demand for tickets to major events has grown at a much greater rate than the capacity of the venues at which they are held. This increase in demand has led to popular events commonly selling out within minutes of going on sale, and to various, sometimes illegal, forms of secondary markets for tickets such as "scalping". It is an area which is fraught with potential legal, ethical and economic issues and the competing interests of artists, promoters, scalpers, fans and the general public. Different strategies and rules have been trialled by event promoters, legislated by local and central governments, and even mooted by academics, as ways to better manage the sale of tickets to major events. These range from ticket sale limits, staggered ticket releases and anti-scalping laws, through to ticket "lotteries" and auctions, and even suggestions of a futures market for tickets. This paper will present a preliminary examination of several of these strategies for selling tickets to major events using computer simulations of a ticket market. It will examine how different rules and forms of ticket markets can impact on the average price paid by purchasers, the variation in prices paid by purchasers, and the return for the event promoters.
\end{abstract}

Keywords: Simulation of markets, event ticketing, derivatives 


\section{INTRODUCTION}

Tickets for major sporting, musical and cultural events, particularly those held in large cities, regularly sell out. This often occurs within hours (sometimes within minutes) of going on sale. Within hours of selling out, tickets can be found for sale on auction websites such as ebay and Trademe, normally at highly inflated prices. Although ticket scalping has existed for many years, the ability to buy and sell tickets over the internet, without having to queue for large periods of time to buy, or stand outside the gate of the venue to sell, has made the process much easier and more widespread.

The fact that scalpers can sell tickets at a premium would suggest that tickets must be priced too low. However, when pricing tickets, promoters are trying to maximise their revenue by selling their entire allocation of tickets. Ticket sales are not underwritten in the same way that a stock issue is, so they bear the risk of not selling all of the tickets. There is also the potential "social externality", as described by Becker (1991), where an event that has not sold many tickets creates a negative perception in the eyes of the public, and the enjoyment of those who attend. This can also negatively affect futures ticket sales for the event and/or the promoter. A sold out event also maximises complementary revenue (food, parking, merchandise etc).

Ticket pricing and selling has multiple stakeholders, each with competing interests. In economic terms we are dealing with a monopoly, since a single promoter will have all of the tickets to sell; a perishable product, since the tickets are of no value after the event has occurred; and excess demand, since the demand for tickets outstrip supply.

This paper will describe some preliminary work on simulating markets for event tickets. It examines selling tickets in four scenarios: a flat price with and without a secondary market, an auction process and a derivative-based process. Although this is not an exhaustive list of possible methods for selling tickets, it is intended to be a starting point for the research.

\section{LITERATURE REVIEW}

Ticket pricing is not an exact science. Although models for supply and demand, such as those by Busch and Curry (2010) do exist, they do not fully explain pricing choices or conclusively demonstrate a most efficient strategy for the sale of event tickets. For example, one might consider that a promoter will only be interested in maximising revenues through the highest possible price. However, Eichhorn and Sahm (2010), while examining the pricing of tickets within a monopoly framework in order to answer the question: "why were FIFA World Cup tickets so cheap?" conclude that:
...given that tickets are a normal commodity, higher admission charges lower the (expected) willingness to cheer among spectators. Put differently, setting high ticket prices drives out high-quality fans, beclouds the atmosphere, and, hence, leads to a loss of revenue in markets that suffer from low emotions ... Moreover, the type structure intended by low ticket prices can only be maintained if the resale of tickets in the black market is credibly prevented.

They argue that what appears as under-pricing of tickets in a basic supply and demand model is in fact a profit maximisation behaviour once consumer psychology is taken into account. Even so, a high income fan who missed out on tickets will have different views on the effectiveness of the World Cup pricing strategy from those of a fan who would not be able to afford a ticket under a different pricing scheme. With this in mind, the intention of this research will be as much about stimulating debate into market structures as it will be about finding an "optimal" one.

One important consideration in the pricing and market structure of event ticketing is the secondary market, and in particular the role of "scalpers" (those who buy additional tickets with the intention of on selling them at a profit). Karp and Perloff (2005) found that if a monopoly supplies a perishable good, such as event tickets, and is not able or willing to price discriminate, then it benefits from resellers. They argue that promoters may actually be better off in a market with scalpers. Swofford (1999) suggests that another reason for why a producing firm may not wish to stop ticket scalpers is that the ticket scalper's cost function may be lower than producing firm's cost function. They may have lower transaction and information costs. In the case of a professional scalper, (as opposed to an opportunist concert goer), they will also be able to spread costs over multiple events. However, Loewenstein (2010) writes about the outrage of consumers over 
several high profile instances of "ticket sniping software" jumping the queue to buy large quantities of tickets ahead of fans and then reselling at very high mark-ups.

Happel and Jennings (2002) put forward the idea of a derivative market for tickets. They note that this is an idea that would completely change the market paradigm, but they believe to have both financial and philosophical advantages, in terms of price and access to tickets. This concept was extended by Sainam et.al. (2010), where they examine the scenario of major sports finals, where tickets sell out far in advance of the finalists being known. They propose that fans could buy an option on a ticket, then choose whether to exercise it at a later date, and provide an empirical example where the profits from using options exceeded those from advance selling and pricing after finalists are known, although they draw a distinction between "team-based fans" and "game-based fans". This paper will look at one simple derivative strategy, but with the intention of moving towards more exotic options and strategies in future research.

Empirical research into markets and pricing has typically used supply and demand models, such as first order differential equations, to solve the profit maximisation problems (for example Busch and Curry (2010)). However, an alternative approach is to use computer simulation to examine market mechanisms. Hoffmann et.al. (2007) discuss current and future trends in the simulation of markets. Although they focus mainly on simulating stock markets, they provide some generic information that is applicable to simulating other kinds of markets. A more specific and relevant example of simulating a market is Cho et.al. (2008). They simulated an agent system for online ticket resale that focused on the secondary market for tickets and different variations of an auction process. They found that agent negotiation helped to stabilise ticket prices and was preferred to an auction process. In both of these examples, computer simulation provided a more effective examination of the market process and differential equations or other empirical analyses.

Lunander (2002), Scalas and Cincotti (2004) both write about simulating auctions. Of particular interest is the way in which each of these pieces of research used Weibull distributions for simulating auction prices. Each chose the Weibull distribution as it had a known probability density function and could provide a useful model of decay, mirroring the range of pricing preferences for auction participants. For modelling ticket pricing it is useful due the shape of the curve. For the same reason it can also be used for modelling the timing of purchases. For a high demand event, most tickets sell in a very short space of time, soon after they are released.

\section{METHODOLOGY}

The simulation was written using the R statistical software programme (http://cran.r-project.org). The key distribution for the simulations is the Weibull distribution. The probability density functions for the Weibull distribution is:

$$
f(x)=\frac{k}{\lambda}\left(\frac{x}{\lambda}\right)^{k-1} \exp \left[-\left(\frac{x}{\lambda}\right)^{k}\right]
$$

where $k$ is the shape parameter and $\lambda$ is the scale parameter. This gives:

$$
\begin{aligned}
& \mu=\lambda \Gamma\left(1+\frac{1}{k}\right) \\
& \sigma^{2}=\lambda^{2} \Gamma\left(1+\frac{2}{k}\right)-\mu^{2}
\end{aligned}
$$

By choosing a shape parameter between zero and one provides a decay curve. This is used to model the purchase premium, the amount beyond a flat ticket price that a consumer would be prepared to pay for a ticket, and also to model the reaction time of consumers to the release of tickets (i.e. how long it takes them to attempt to purchase).

In order to restrict the scope of the study, a number of assumptions were made. For the purpose of the simulation it was assumed that the event in question has 50,000 available seats and that there is excess demand, with 80,000 consumers willing to pay the flat rate ticket price or more. The flat rate ticket price was set at $\$ 100$. For this preliminary study this figure of 80,000 is held constant. Further testing of the impact of this figure, and the other assumptions will be conducted as part of future research. 
For this paper, four models are investigated:

- $\quad$ Flat price without scalping

- $\quad$ Flat price with scalping

- $\quad$ Auction, selling to the highest bids

- Consumer purchases tradeable option, then flat price set later

The flat price models are the two that are most commonly seen pricing models, where the event promoter sets a flat price where they are trying to achieve the maximum price whilst still selling the full allocation of tickets. Since a promoter does not know how much the premium (if any) there is, they can't just raise the price. The flat rate model is tested with and without a secondary market (ticket scalping). If a consumer goes to buy a ticket and there is a large differential between the flat price and the price they would be prepared to pay they buy an additional ticket to sell on for a profit.

The auction method allocates the tickets to the 50,000 highest bids. The reaction time of the consumers is no longer a factor as it is assumed that they will all place a bid within the allotted time. It assumes that the event promoter has the infrastructure required for consumers to register a bid price for their ticket and for these to be sorted and sold at different prices. In some markets, this would not be possible due to legislation against differentiated pricing.

The final method involves buying a call option. For the initial investigation, this is a simple starting point. There are possibly other derivatives, including futures contracts, Asian options, and Lookback options that may be more suitable for event ticketing, but add additional complexity to the analysis. The option would be tradeable. This model follows same rationale as other derivative markets, with the option being a contract on the underlying asset (in this case the event ticket). This seems particularly useful for major sporting events (such as finals) where the participants are not known at the time that tickets normally go on sale. The options can be valued using the Black-Scholes model (below), although for the initial simulations, a fixed price of $\$ 10$ is allocated, followed by a period of random walk trading. The value of the strike price is then calculated and set as the flat price for the ticket.

$$
\begin{aligned}
& c=S_{0} N\left(d_{1}\right)-K e^{-r T} N\left(d_{2}\right) \\
& d_{1}=\frac{\ln \left(S_{0} / K\right)+\left(r+0.5 \sigma^{2}\right) T}{\sigma \sqrt{T}}, d_{2}=d_{1}-\sigma \sqrt{T}
\end{aligned}
$$

One thousand iterations of the simulation were run, with consumer timing and pricing premiums drawn from a Weibull distribution. The initial price and the secondary market price was calculated for each pricing model and recorded. For this preliminary research, the means and confidence intervals of the prices will be presented. However, future work will examine the distributions, consumer utility functions and market behaviour more closely.

\section{RESULTS}

Table 1 shows the average price received by promoter (primary price), the average price paid in the secondary market (secondary price).

The simulations showed a range of average prices. The 1000 trials produced very low standard errors for these estimates, so confidence intervals were not reported. The results should also be considered a work in progress, with further results to be presented at the conference.
Table 1. Simulation results

\begin{tabular}{|l|c|c|}
\hline Model & $\begin{array}{l}\text { Average } \\
\text { Primary Price }\end{array}$ & $\begin{array}{l}\text { Average } \\
\text { Secondary } \\
\text { Price }\end{array}$ \\
\hline Flat price no scalping & 100 & - \\
\hline Flat price, scalping & 100 & 132 \\
\hline Auction & 120 & - \\
\hline Option & $110^{*}$ & $120^{*}$ \\
\hline
\end{tabular}

The flat price structure resulted in the lowest price received by the promoters. As expected the auction pricing model resulted in a higher price received by the promoters, since it was able to price discriminate, and sales were based on the highest bids rather than the fastest responses. It was assumed that since those who bid the highest were the ones who received the tickets that there would be a limited (or no) secondary market. 
The call option provided the most interesting results, with a higher average primary price, but a lower average secondary price than the other models. To some degree it provided a balance between a flat price structure and an auction structure.

\section{DISCUSSION}

The results showed clear differences in the prices faced by consumers and received by promoters from the different pricing models for event ticketing. In examining the results it should be noted that:

1. This is preliminary research, so the models and results are intentionally kept basic, and

2. The intention of the research is to fact-find and generate discussion ideas about ticket pricing and markets, rather than to draw strong conclusions about

As expected, the flat rate pricing structure provided the cheapest price for consumers (but therefore the lowest return to the promoter). By eliminating scalping the tickets went to the fastest (or luckiest) consumers rather than those willing to pay the highest price. Whilst there are possible gains in utility from this, and as previously mentioned in the article by Eichhorn and Sahm (2010), even an argument that this is a form of profit maximisation, it still suggests that the tickets are being underpriced. The difficulty for the promoter is that they do not have an explicit knowledge of what consumers will be prepared to pay, so are relying on estimating a flat price based on the event, and their experience of previous events. Flat rate pricing with scalping provides consumers who miss out on the initial allocation but have a high premium that they are prepared to pay for tickets the chance to buy tickets. However, it can also motivate purchasers to buy additional tickets to scalp, meaning fewer purchasers can actually buy their tickets from the primary market. By comparison the auction process provided a higher price for the promoter by operating the more familiar mode of supply and demand, where those who were prepared to pay the highest prices received the tickets. Economically, this seems like a sensible approach, but it should be noted that the literature on social externalities (see Becker (1991)) and consumer psychology suggest that in the long term these prices gains will deteriorate (and result in fewer ticket sales).

The call option provided a slightly higher primary price but a lower secondary price. This would suggest that it is operating in a more efficient manner than the other models. However it was a very simple model and further investigation into its operation is required. It is also only one of a number of different options, such as Asian options, Lookback options, and other exotic derivatives that could potentially perform a similar role in the sale of tickets. Furthermore, the use of a derivative-based ticket market is slightly more complex than the other models, so it would be more difficult to apply to the current sale of tickets. It will take more effort to promote and educate consumers about. Happel and Jennings (2002) write that the main trade-off with moving towards a derivative market for event tickets will be to provide it in a way that is intuitive to consumers and encourages them to buy tickets and participate in a derivative market (although a big part of that will be to not refer to it as a derivative market unless the event is targeted at professional finance workers).

Marketing and consumer psychology play a big part in the success of large-scale events. Any change in the way that such events are ticketed would need to be thoroughly researched. Even as an academic exercise, one of the possible next steps in this research would be to incorporate historical financial information and to survey and interview those who regularly purchase tickets. Beyond this, there are other factors to consider, such as different market models, the effect of different simulation methods.

\section{CONCLUSION AND RECOMMENDATIONS}

This paper presented some preliminary research into simulating event price ticketing. Some of the results were expected; for example flat rate pricing provided a lower price to promoters than an auction process, and rewarded consumers who were faster (or luckier) in the early purchase of tickets, rather than those prepared to pay the most. However, even though some of the results were not surprising, the performance of a simple call option styled derivative for the future purchase of an event ticket suggested that further research into simple derivative-based ticketing could provide a balance between the pricing desires of consumers and event promoters.

There is considerable potential for further work in the area of ticket pricing and markets. This includes experimenting with different models and distributions, and adding information from other sources, such as 
Walker, Simulating markets for ticket sales to major events

historical financial and supply and demand data, and a survey of consumers on purchasing preferences and behaviours.

\section{REFERENCES}

Becker, G.S. (1991). A note on restaurant pricing and other examples of social influences on price. Journal of Political Economy, 99(5), 1109-1116.

Busch, L.A. and Curry, P.A. (2010). Ticket pricing and the impression of excess demand. Economic Letters, 111, 40-42.

Cho, J.H., Kim, H.S., Choi, H.R., and Jung, J.U. (2008). Agent system for online ticket resale. In N.T Nguyen, G.S. Jo, R.J. Howlett, and L.C. Jain, Agent and Multi-Agent Systems: Technologies and Applications, Lecture Notes in Computer Science, Springer Berlin / Heidelberg, 4953, 614-623

Eichhorn, C. and Sahm, M. (2010). Why were FIFA World Cup tickets so cheap? Monopoly pricing, demand quantity and two-sided markets. Journal of Economic Psychology, 31, 212-217.

Happel, S.K. and Jennings, M.M. (2002). Creating a futures market for major events tickets: Problems and prospects. Cato Journal, 21(3), 443-461.

Hoffmann, A. O. I., Jager, W. and Von Eije, J. H. (2007). Social simulation of stock markets: Taking it to the next level. Journal of Artificial Societies and Social Simulation 10(2)7 http://jasss.soc.surrey.ac.uk/10/2/7.html.

Karp, L. and Perloff, J.M. (2005). When promoters like scalpers. Journal of Economics and Managements, 14(2), 477-508.

Loewenstein, A. (2010). Ticket sniping. Journal on Telecommunications and High Technology Law, 8(1), 243-276.

Lunander, A. (2002). Procurement bidding in first-price and second-price, sealed-bid auctions within common-value paradigm. Computational Economics, 19, 227-244.

Sainam, P., Balasubramanian, S. and Bayus, B.L. (2010). Consumer options: Theory and an empoircal application to a sports market. Journal of Marketing Research, 47(3), 401-414.

Scalas, E., and Cincotti, S. (2004). A double-auction artificial market with time-irregularly spaced orders. Computing in Economics and Finance, 225, http://econpapers.repec.org/RePEc:sce:scecf4:225.

Swofford, J.L. (1999). Arbitrage, speculation, and public policy toward ticket scalping. Public Finance Review, 27, 531-540. 